\title{
Optimising the Mizoroki-Heck reaction of cyclic allyl amines: gram-scale synthesis of Preclamol without protecting groups
}

Joseph B. Sweeney, ${ }^{+\tau_{*}}$ Kirsty Adams, ${ }^{\dagger}$ Robert Crook, ${ }^{\#}$ Julien Doulcet, ${ }^{\dagger}$ Bimod Thapa $^{\dagger}{ }^{\text {and }}$ Fanny Tran"

†Department of Chemical Sciences, University of Huddersfield, Huddersfield HD1 3DH UK

\#Pfizer Ltd Ramsgate Road Sandwich Kent CT13 9NJ

"Department of Chemistry, University of Reading RG6 6AP UK

*Corresponding author: j.b.sweeney@hud.ac.uk

Abstract. Though a widely used metal-catalysed cross-coupling process, the MizorokiHeck ('MH') reaction can be a capricious transformation. This is particularly true for oxidation-prone alkene substrates containing ligating heteroatoms, as in the case of $\mathrm{N}$ alkyl tetrahydropyridines whose $\mathrm{MH}$ reactions have been under-explored, due to the many side-reactions which hamper the process. Since the products of tetrahydropyridine Heck reactions are direct precursors to potent pharmacophores, and therefore of commercial value, this is a significant drawback and limitation. We report here the results of our study designed to deliver an optimized, scalable $\mathrm{MH}$ procedure for $\mathrm{N}$-alkyl tetrahydropyridines, and its exemplification in a gram-scale synthesis of the drug substance Preclamol.

Keywords. Catalysis, tetrahydropyridines, Mizoroki-Heck reaction, aryl piperidines, CNS drugs.

\section{Introduction}

Amongst the many catalytic processes available to the modern synthetic chemist, the Mizoroki-Heck ('MH') reaction ${ }^{1}$ is of special significance as the first reported method ${ }^{2}$ which enabled direct, substoichiometric catalytic modification of simple alkenes: the overall transformation is effectively a $\mathrm{CH}$ activation process, in which an aryl unit is inserted into an $\mathrm{sp}^{2}-\mathrm{CH}$ bond (Scheme 1). The reaction has been intensely studied and optimised, and a wide range of coupling partners (aryl halides, triflates, sulfonates, diazonium salts, iodonium salts), alkenes and catalysts has been used productively in the process, with many successful applications to the production of complex natural and synthetic targets. ${ }^{3}$ Notwithstanding the proven synthetic power of the transformation, there are several known limitations to the process; thus, the reactions are often heterogeneous (precluding detailed kinetic and mechanistic analysis), and some alkene classes are unreliable and capricious substrates. Unsaturated amines fall into this category, often undergoing inefficient transformations which require high susbtrate or catalyst loading; this is especially the case 
for cyclic allylamines (such as tetrahydropyridines ${ }^{4}$, and pyrrolines ${ }^{5}$ ), which react efficiently only if the lone-pair of electrons on nitrogen is delocalized into an electron-withdrawing protecting group. This limitation is a particular drawback, since the method in theory allows for direct synthesis of $\mathrm{N}$-alkyl piperidines and pyrrolidines, a class of heterocycle with privileged pharmacological status, particularly in CNS-active compounds such as the marketed drugs paroxetine ${ }^{6}$ and niraparib ${ }^{7}$ (Figure 1); however, to date, the limitations of $\mathrm{MH}$ reaction of tetrahydropyridines (lack of regioselectivity, over-reaction, multiple isomerisation pathways and low yields) have severely restricted the use of this potentially impactful catalytic process.

Figure 1. Aryl piperidines: privileged biological motifs accessible from tetrahydropyridines

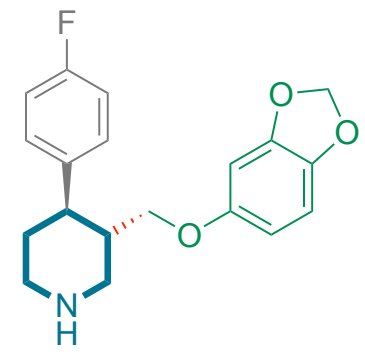

Paroxetine (Seroxat ${ }^{\circledR}$ ) 2007 sales $>\$ 1$ bn

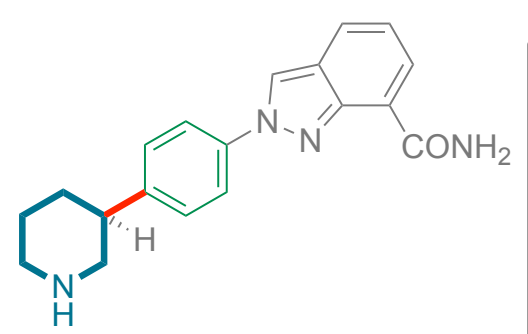

Niraparib (Zejula ${ }^{\circledR}$ ) Q1 2017 sales $>\$ 25 M$

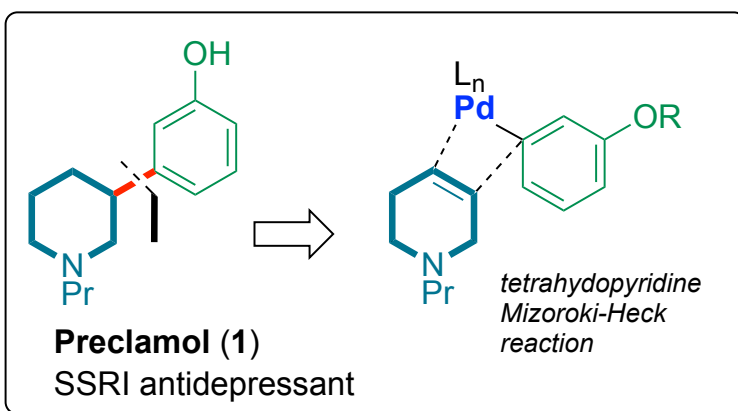

3-Aryl piperidines are a class of heterocycle with particular biological potency, and Preclamol $^{8}$ occupies a pre-eminent position as a first-in-class antipsychotic drug substance. The compound is a dopamine autoreceptor agonist, and it has been used in man for the treatment of schizophrenia. ${ }^{9}$ To access this compound, and other related biologically active compounds, a range of heterocycles can function as chemical feedstocks for catalytic processing (Figure 2).

Figure 2. Catalytic strategies for the synthesis of Preclamol 
a. Pyridine cross-couplings ${ }^{10-12}$

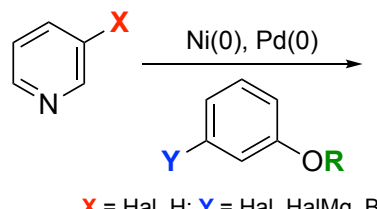

$X=\mathrm{Hal}, \mathrm{H} ; \mathrm{Y}=\mathrm{Hal}$, HalMg, BR $;$ R = Me, H

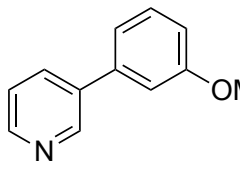

b. Piperidine cross-coupling ${ }^{13}$

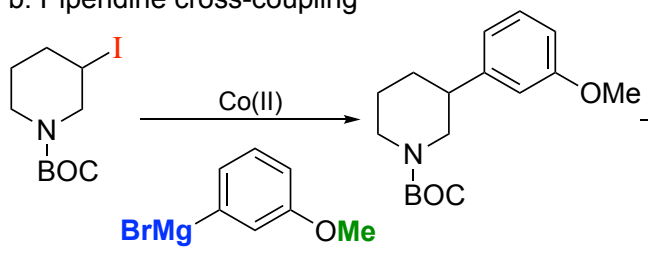

c. Tetrahydropyridine cross-coupling ${ }^{4 a}$

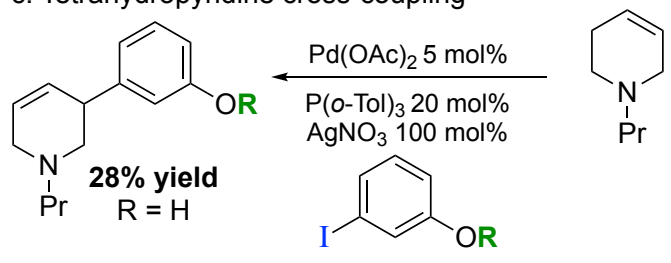

d) This work: low catalyst-loading, protecting group-free

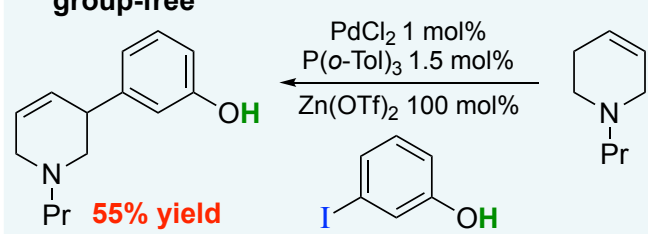

Thus, several catalytic methods using pyridines as feedstocks have been used to access the Preclamol core (Figure 2a), including nickel-catalysed Kumada ${ }^{10}$ and Suzuki-Miyaura coupling ${ }^{11,12}$ of 3-bromopyridine, and pyridine $\mathrm{C}-\mathrm{H}$ activation. ${ }^{13}$ In these reactions, further non-trivial steps (alkylation, reduction, etc.) are required to access the biologically active products. Cross-coupling of non-aromatic amines have been less widely used to access the 3-arylpiperidine core, with the $\mathrm{Co}(\mathrm{II})$-catalysed coupling of 3-iodo- $\mathrm{N}$-Boc-piperidine with Grignard reagents a notable example of such a strategy (Figure $2 b$ ). ${ }^{14}$

In theory, the use of tetrahydropyridines (available in bulk from commercial sources) in a Mizoroki-Heck reaction would allow highly efficient access to 3-aryl piperidines, and the method has been used by Hallberg et al. to access Preclamol (Figure 2c). ${ }^{4 a}$ However, the method reported by these authors delivered the target 3-arylpiperidine inefficiently, and required high ligand loading and stoichiometric $A g(I)$ as an additive. ${ }^{15}$ Since this pioneering report, there have been no reports of $\mathrm{MH}$ reactions of alkyl tetrahydropyridines, which is likely a reflection of the poor yields obtained in these transformations, presumably due to the tendency of $\mathrm{N}$-alkyl tetrahydropyridines to undergo palladium-catalysed side reactions (such as aromatisation, giving pyridiniums) under the heterogeneous reaction conditions. Though in theory $\mathrm{N}$-alkyl 3-arylpiperidines 2 (Figure 3) are available via $\mathrm{MH}$ reaction of $\mathrm{N}$ acyl tetrahydropyridines, in practice this is difficult, as shown by the work of Correia et al, ${ }^{5 b}$ due to the tendency for these reactions to deliver mixtures of enamines (isolated as hydrated products 3 and 4 ), which limits the utility of the reactions.

Figure 3. Regiochemical divergence in Mizoroki-Heck reactions of tetrahydropyridines 


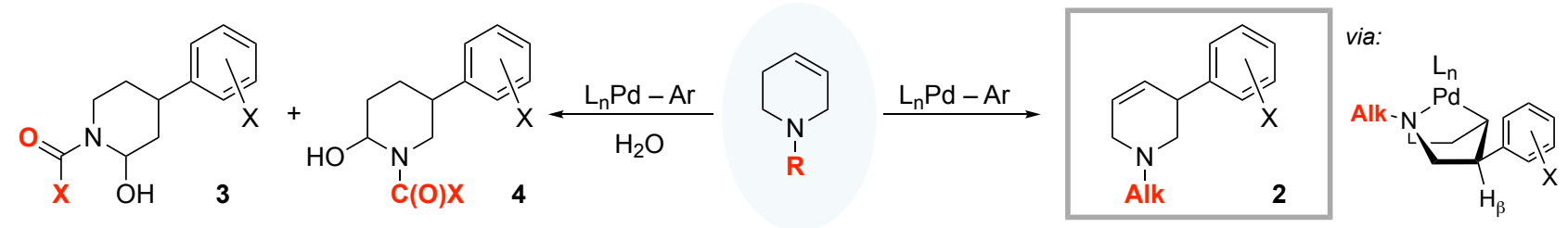

Given the ready commercial availability of $N$-alkyl tetrahydropyridines, and the great utility of 3-arylpiperidines, we undertook a study of the factors affecting these complex $\mathrm{MH}$ reactions, and report an improved and simplified synthesis of Preclamol using our new method.

\section{Results and discussion}

Our project had three key aims: firstly, to reduce the catalyst loading for $\mathrm{MH}$ reaction to $\leq 1$ mol\%; secondly, to avoid the use of a silver additive; thirdly, to develop a method involving no protecting groups. In particular, the latter goal was a demanding one, due to the known challenges in using phenols in palladium-catalysed reactions, ${ }^{16}$ but was one which offered significant mass balance advantages if successful.

Table 1: Initial optimisation of the Mizoroki-Heck reaction of tetrahydropyridine 6

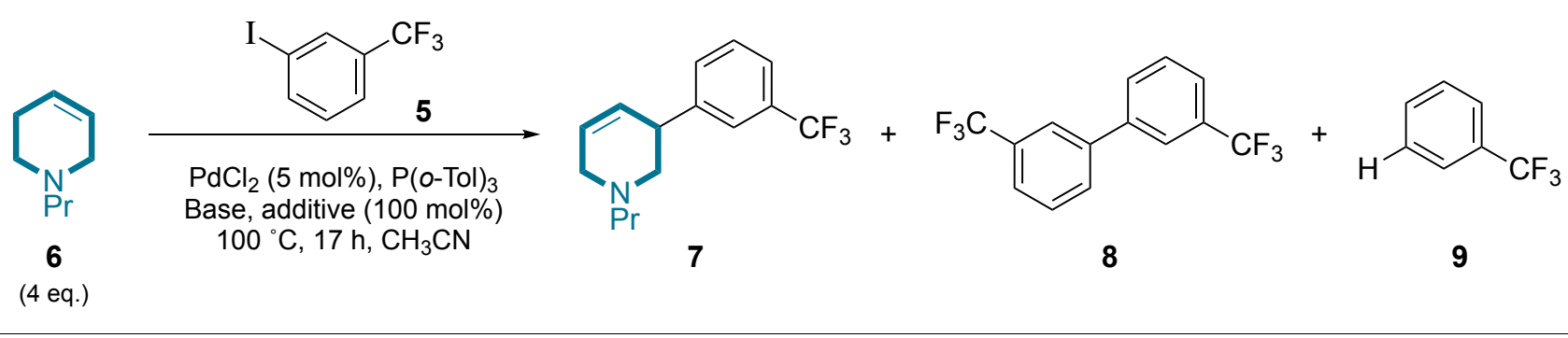

\begin{tabular}{|c|c|c|c|c|c|c|c|}
\hline \multirow[t]{2}{*}{ Entry } & \multirow[t]{2}{*}{$\mathrm{P}(\mathrm{o}-\mathrm{Tol})_{3} / \mathrm{mol} \%$} & \multirow[t]{2}{*}{ Base } & \multirow[t]{2}{*}{ Additive } & \multirow[t]{2}{*}{ Conversion/\% } & \multicolumn{3}{|c|}{ Yield/\% } \\
\hline & & & & & 7 & 8 & 9 \\
\hline 1 & 20 & - & $\mathrm{AgNO}_{3}$ & 100 & $18^{a}$ & 16 & 62 \\
\hline 2 & 40 & - & $\mathrm{AgNO}_{3}$ & 100 & 10 & 9 & 78 \\
\hline 3 & 10 & - & $\mathrm{AgNO}_{3}$ & 100 & 27 & 10 & 49 \\
\hline 4 & 5 & - & $\mathrm{AgNO}_{3}$ & 100 & 35 & 11 & 42 \\
\hline 5 & 5 & $\mathrm{DMPip}^{\mathrm{b}}$ (5 eq.) & $\mathrm{AgNO}_{3}$ & 92 & 39 & 3 & 16 \\
\hline 6 & 5 & DMPip (1 eq.) & AgOTf & 100 & 49 & 7 & 19 \\
\hline 7 & 5 & DMPip (5 eq.) & $\mathrm{Cu}(\mathrm{OTf})_{2}$ & 100 & 55 & 3 & 6 \\
\hline 8 & 7.5 & DMPip (1 eq.) & $\mathrm{Cu}(\mathrm{OTf})_{2}$ & 100 & 59 & 3 & 11 \\
\hline 9 & 5 & DMPip (1 eq.) & $\mathrm{Cu}(\mathrm{OTf})_{2}$ & 100 & 58 & 2 & 8 \\
\hline 10 & 7.5 & DMPip (1 eq.) & $(\mathrm{CuOTf})_{2} \cdot \mathrm{PhCH}_{3}$ & 98 & 58 & 4 & 12 \\
\hline
\end{tabular}




\begin{tabular}{|c|c|c|c|c|c|c|c|}
\hline 11 & 7.5 & DMPip (1 eq.) & $\mathrm{Zn}(\mathrm{OTf})_{2}$ & 100 & 52 & 2 & 28 \\
\hline 12 & 7.5 & DMPip (5 eq.) & $\mathrm{Zn}(\mathrm{OTf})_{2}$ & 100 & 61 & 2 & 10 \\
\hline
\end{tabular}

Preliminary studies of the $N$-alkyl THPy Mizoroki-Heck reaction confirmed the limitations of the reaction: the heterogeneous process delivered a multitude of products in addition to the desired arylated target, predominantly pyridinium species (and derived compounds) arising from metal-catalysed oxidation. We therefore embarked upon a detailed analysis of the parameters of this reaction ( $\mathrm{Pd}$ catalyst, ligand, base, solvent, additive, temperature); to simplify the analysis of this complex reaction, we chose (3-iodo)benzotrifluoride $\mathbf{5}$ as a model substrate, using ${ }^{19} \mathrm{~F}$ NMR to study its reaction with N-propyl tetrahydropyridine 6 . In this manner, we hoped to optimise the yield of the target product (7), and quickly identify and quantitatively estimate the side-product profile of the reaction, thus giving valuable insights into the reaction mechanism and facilitating optimisation. A summary of the salient data obtained from the initial optimisation phase is given in Table 1.

The next phase of optimisation was focused on improving the efficiency of the transformation, by reducing the loadings of catalyst and substrate, and on the reaction temperature (Table 2).

Satisfyingly, the use of $1 \mathrm{~mol} \% \mathrm{PdCl}_{2}$ was effective without reducing the yield of 7 (Table 2, entry 3 ), though a $0.5 \%$ catalyst loading was less efficient (Table 2, entry 2). Variation in the stoichiometry of tetrahydropyridine had a less pronounced effect on the reaction, with a $50 \%$ decrease in loading having little negative impact on the yield of 7 (Table 2, entry 5). Finally, lowering the temperature to $70{ }^{\circ} \mathrm{C}$ proved to have a positive effect on the yield (Table 2, entries 7 and 8).

Table 2: Optimisation of $\mathrm{MH}$ reaction of 6: influence of temperature, catalyst loading and stoichiometry

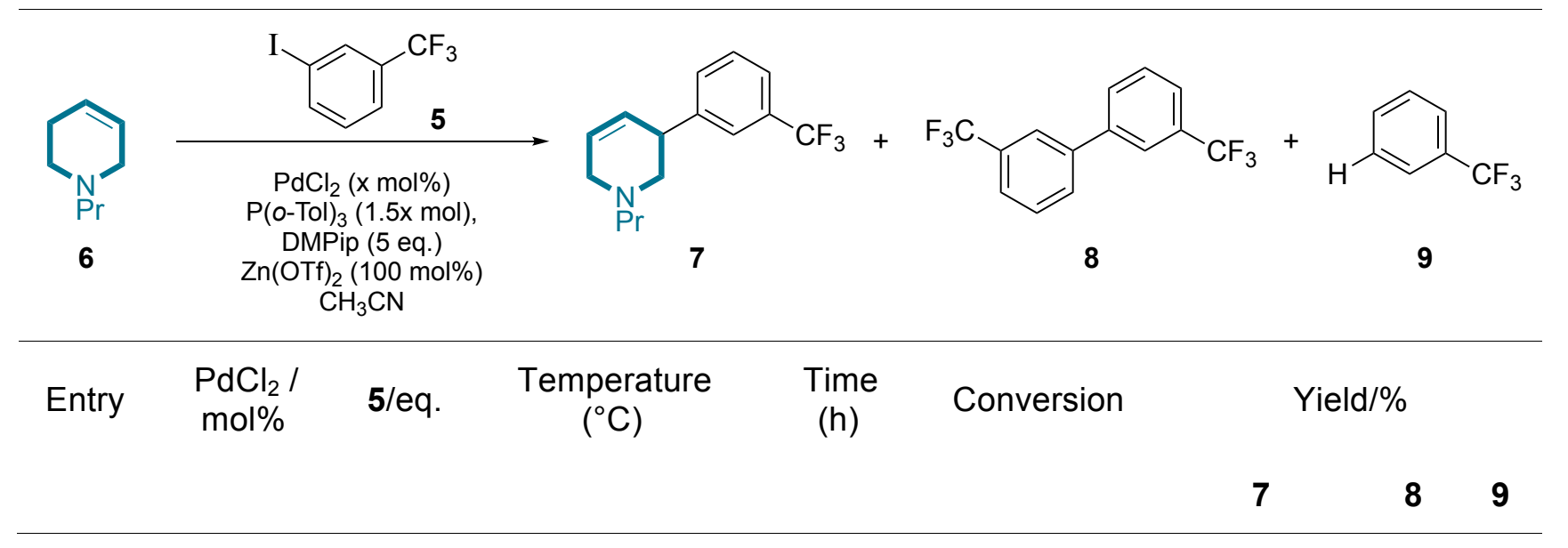




\begin{tabular}{ccccccccc}
\hline 1 & 5 & 4 & 100 & 17 & 100 & $61^{\mathrm{a}}$ & 2 & 10 \\
2 & 0.5 & 4 & 100 & 17 & 95 & 56 & 2 & 10 \\
3 & 1 & 4 & 100 & 17 & 100 & 60 & 1 & 9 \\
4 & 5 & 3 & 100 & 17 & 100 & 63 & 2 & 9 \\
5 & 5 & 2 & 100 & 17 & 100 & 59 & 3 & 8 \\
6 & 5 & 1.5 & 100 & 17 & 100 & 56 & 4 & 8 \\
7 & 1 & 3 & 70 & 120 & 100 & 67 & 1 & 6 \\
8 & 1 & 2 & 70 & 120 & 100 & $62\left(55^{\mathrm{b}}\right)$ & 2 & 6 \\
9 & 1 & 1.5 & 70 & 120 & 89 & 57 & 1 & 5 \\
\hline
\end{tabular}

Armed with an optimised procedure, we turned to the synthesis of Preclamol, and observed that using either benzyl ether 10a or free phenol 10b, $\mathrm{MH}$ reactions were significantly improved compared to the previously reported procedure: in particular, $\mathbf{1 1 b}$ was obtained in $55 \%$ yield, compared to $28 \%$ reported by Hallberg et al. (Table 3, entry 3 ). In addition to the desired product $11 \mathbf{a}$ and $\mathbf{1 1 b}$, on the larger scale of these reactions, we now also detected the presence of novel diarylated alkenes $12 \mathbf{a}$ and $\mathbf{1 2 b}$.

Table 3: Optimised $\mathrm{MH}$ reaction of 6

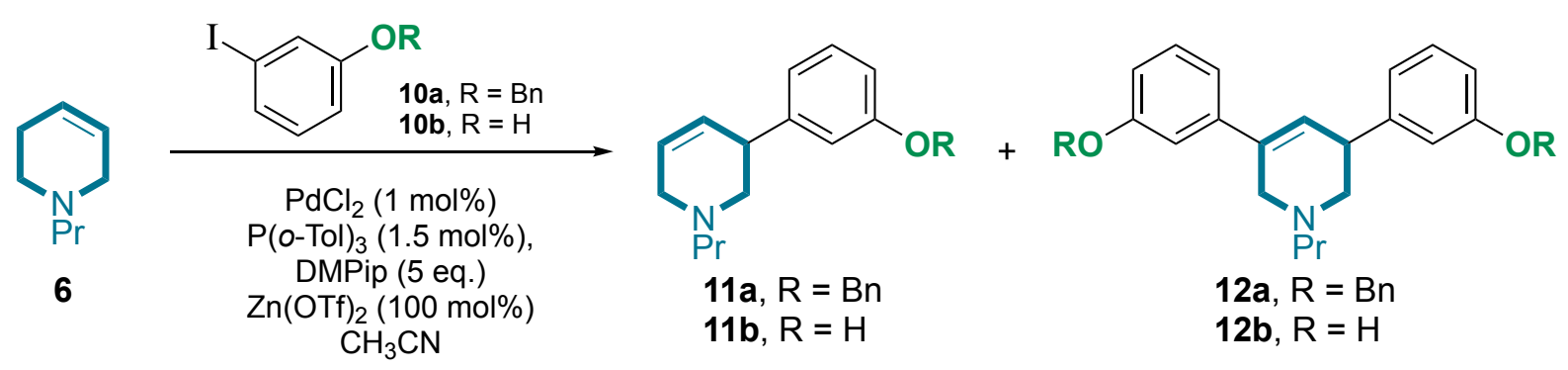

\begin{tabular}{|c|c|c|c|c|}
\hline Entry & 6 (eq) & $\mathbf{R}$ & Yield 11/\% & Yield $12 / \%$ \\
\hline 1 & 4 & $\mathrm{Bn}$ & $11 \mathrm{a}, 55^{\mathrm{a}}$ & $12 a, 5^{b}$ \\
\hline 2 & 2 & $\mathrm{Bn}$ & $11 a 49$ & $12 a, 13$ \\
\hline 3 & 4 & $\mathrm{H}$ & $11 \mathrm{~b}, 55^{\mathrm{c}}$ & $12 b, 6$ \\
\hline 4 & 2 & $\mathrm{H}$ & 11b, 49 & $12 b, 10$ \\
\hline
\end{tabular}

When performed on a $12.5 \mathrm{mmol}$ scale (Scheme 1), the extent of side-reactions involved in $\mathrm{MH}$ reactions of $\mathrm{N}$-alkyl tetrahydropyridines becomes apparent, with side-products derived from other possible palladium $\sigma$ intermediates: thus in addition to $\mathbf{1 1 b}$, and diarylated amine $\mathbf{1 2 b}$,

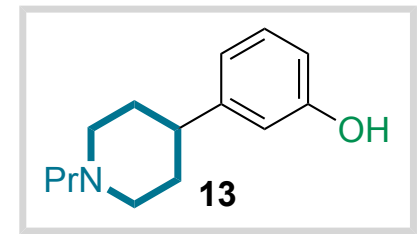


Preclamol (1) itself and saturated amine 13 were observed in small amounts, the latter products presumably formed via reductive $\mathrm{MH}$ processes. ${ }^{17}$ Hydrogenation of either $11 \mathrm{a}$ or 11b gave Preclamol in 49-55\% overall yield.

Scheme 1. Improved synthesis of Preclamol 1
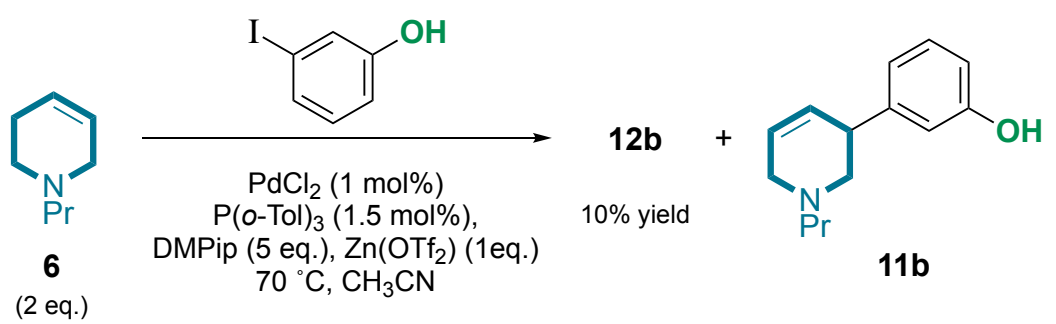

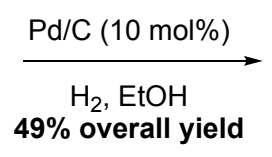
$49 \%$ overall yield

$11 b$

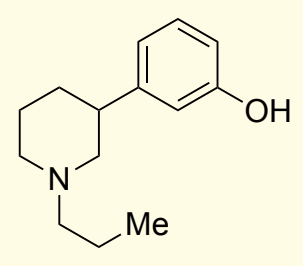

Preclamol

\section{Conclusion}

In summary, we have designed and implemented an improved method for the MizorokiHeck reaction of $N$-propyl tetrahydropyridine, which is more cost-effective, milder, more functional group tolerant, and which efficiently provides access to gram quantities of Preclamol in good overall yield. Developing an in-depth understanding of the detailed mechanistic features of this complex heterogeneous catalytic reaction is a focus of our current research.

\section{Materials and methods}

Full experimental details and key spectra for products can be found in the Supplementary Material.

\section{Acknowledgements}

We thank the University of Huddersfield for funding of this research programme.

\section{References}

1. S. Braese, A. de Meijere, in: (Eds.) A. De Meijere, , S. Brase, M.Oestreich, MetalCatalyzed Cross-Coupling Reactions and More 2 (2014) 533; The Mizoroki-Heck Reaction, M. Oestreich (Ed.), Wiley: Chichester, 2009.

2. (a) T. Mizoroki, K. Mori, A. Ozaki, Bull. Chem. Soc. Jpn. 44 (1971) 581. (b) R. F. Heck, J. P. Nolley, J. Org. Chem. 37 (1972) 2320 
3. For a recent use of a Heck reaction of a cyclic olefin in the synthesis of a natural product see: J. Nugent, M. G. Banwell, B. D. Schwartz, Org. Lett. 18 (2016) 3798.

4. (a) K. Nilsson, A. Hallberg, J. Org. Chem. 57 (1992) 4015. (b) J. C. Pastre, C. R. D. Correia, Org. Lett. 8 (2006) 1657.

5. Heck reactions of 3-pyrroline carbamates have been studied: (a) C. Sonesson, M. Larhed, C. Nyqvist, A. Hallberg, J. Org. Chem. 61 (1996) 4756. (b) M. J. S. Carpes, C. R. D. Correia, Tetrahedron Lett. 43 (2002) 741. (c) A. C. B. Montes de Oca, C. R. D. Correia, ARKIVOC (2003) 390. (d) A. L. L. Garcia, M. J. S. Carpes, A. C. B. M. de Oca, M. A. G. dos Santos, C. C. Santana, C. R. D. Correia, J. Org. Chem. 70 (2005) 1050; K. Peixoto da Silva, M. Narciso Godoi, C. R. D. Correia, J. Org. Chem. 9 (2007) 2815; F. G. Finelli, M. N. Godoi, C. R. D. Correia, J. Braz. Chem. Soc. 26 (2015) 910.

6. For a recent synthesis of Paroxetine, see: Y. Zhang, Y. Liao, X. Liu, Q. Yao, Y. Zhou, L. Lin, X. Feng, Chem. Eur. J. 22 (2016) 15119.

7. C. K. Chung, P. G. Bulger, B. Kosjek, K. M. Belyk, N.Rivera, M. E. Scott, G. R. Humphrey, J. Limanto, D. C. Bachert, K. M. Emerson Org. Process Res. Dev. 18 (2014) 215; D. J. Wallace, Carl A. Baxter, K.J. M. Brands, N. Bremeyer, S. E. Brewer, R. Desmond, K. M. Emerson, J. Foley, P. Fernandez, W. Hu, S. P. Keen, P. Mullens, D. Muzzio, P. Sajonz, L. Tan, R. D. Wilson, G. Zhou, G. Zhou Org. Process Res. Dev. 15 (2011) 831.

8. S. Hjorth, A. Carlsson, H. Wikström, P. Lindberg, D. Sanchez, U. Hacksell, L.-E. Arvidsson, U. Svensson, J. L. G. Nilsson, Life Sci. 28 (1981)1225; J. Amt, K. P. Bøgesø, A. V. Christensen, J. Hyttel, J.-J. Larsen, and O. Svendsen Psychopharmacology 81 (1983) 199; H. Wikström, D. Sanchez, P. Lindberg, U. Hacksell, L.-E. Arvidsson, A. M. Johansson, S.-O. Thorberg, J. L. G. Nilsson, K Svensson, S. Hjorth, David Clark, A. Carlssone J. Med. Chem. 27 (1984) 1030.

9. C. A. Tamminga, N. G. Cascella, R. A. Lahti, M. Lindberg, A Carlsson, J Neural Transm Gen Sect. 88 (1992)165.

10. S. O. Thorberg, L. Gawell, I. Csöeregh, J. L. G. Nilsson, Tetrahedron 41 (1985) 129.

11. J. L. Nallasivam, R. A. Fernandes, Eur. J. Org. Chem. (2015) 3558.

12. Suzuki-Miyuara coupling of allylic substrates has also been used in enantioselective syntheses of Preclamol: P. Schafer, T. Palacin, M. Sidera, S. P. Fletcher, Nature Commun. 8 (2017), 15762. 
13. M. Ye, G.-L. Gao, A. J. F. Edmunds, P. A. Worthington, J. A. Morris, J.-Q. Yu, J. Am. Chem. Soc. 133 (2011) 19090.

14. (a) L. Gonnard, A. Guérinot, J. Cossy, Chem. Eur. J. 21 (2015) 12797; (b) See also: A. De Filippis, D. G. Pardo, J. Cossy, Lett. Org. Chem. 2 (2005)136.

15. For the first examples of Heck reactions with silver additives, see: (a) K. Karabelas, C. Westerlund, A. Hallberg, J. Org. Chem. 50 (1985) 3896. (b) K. Karabelas, A. Hallberg, J. Org. Chem. 51 (1986) 5286. For the suppression of isomerization by silver additives, see: (c) M. M. Abelman, T. Oh, L. E. Overman, J. Org. Chem. 52 (1987) 4130. (d) M. M. Abelman, L. E. Overman, J. Am. Chem. Soc. 110 (1988) 2328. (e) R. C. Larock, H. Song, B. E. Baker, W. H. Gong, Tetrahedron Lett. 29 (1988) 2919. (f) R. C. Larock, W. H. Gong, J. Org. Chem. 54 (1989) 2047. (e) R. C. Larock, W. H. Gong, B. E. Baker, Tetrahedron Lett. 30 (1989) 2603. (h) R. C. Larock, W. H. Gong, J. Org. Chem. 55 (1990) 407. (i) T. Jeffery, Tetrahedron Lett. 32 (1991) 2121.

16. See, for instance: B. Schmidt,; F. Hölter, A. Kelling, U. Schilde, J. Org. Chem. 76 (2011) 3357, and references therein. For alternative approaches to phenols using Mizoroki-Heck reaction, see: (a) Y. Izawa, D. Pun, S. S. Stahl, Science 333 (2011) 209. (b) Y. Izawa, C. Zheng, S. S. Stahl, Angew. Chem., Int. Ed. 52 (2013) 3672.

17. It has been reported that amines can be effective hydride sources for reductive Heck reactions: S. Raoufmoghaddam, S. Mannathan, A. J. Minnaard, J. G. de Vries, J. N. Reek, Chem. Eur. J. 21 (2015) 18811. 